\title{
Architecture and Narrative: The Formation of Space and Cultural Meaning
}

\author{
Mahbub Rashid \\ University of Kansas, USA
}

Architecture and Narrative: The Formation of Space and Cultural Meaning

By Sophia Psarra

Routledge, 2009

ISBN-13: 978-0415343763

£29.99

Paperback, pp. 285 with illustrations

In Architecture and Narrative, Sophia Psarra studies the geometry and configuration (defined as the structural relationships of parts to other parts and to the whole) of buildings. She also studies how the geometry and configuration of buildings define visual fields of individuals located inside these buildings. Her intention is to show how restrictions imposed on visual fields by geometry and configuration help create meaning. Psarra argues that this meaning is intrinsic to buildings, and is distinct from any other meanings of a building given by some systems of reference external to the building. Consequently, she also studies the interaction between the intrinsic and extrinsic meanings of buildings. Psarra chooses her title Architecture and Narrative because, much like a narrative, a building applies, structures, and represents its materials and contents to create meaning.

In her study, Psarra includes well-known buildings of different scales built for different purposes in different historical periods. On the one hand, she includes the Parthenon, the Erechtheion, and the Barcelona Pavilion, because objects contained inside these buildings are completely integrated with their designs. On the other hand, she includes six museum buildings whose primary purpose is to display objects that have their own narratives in the way they are classified and arranged in space. In addition to these buildings, Psarra also studies four metaphysical stories of Jorge Luis Borges.

Psarra studies the first set of buildings to show how the abstract geometric order (the conceptual) and the structure of visual experience (the perceptual) interact with each other in these buildings to create meaning in the absence of any well-defined program. She studies the second set to show how meaning is created when the conceptual and the perceptual structures of buildings interact with the external conceptual schemes represented by display objects. Psarra studies Borges' texts to show how the construction of meaning of a text informs that of architecture. 
Psarra's description of the geometry and configuration of her case studies is nuanced. She studies different geometric attributes of buildings including: axiality, centrality, symmetry, rhythm, congruence and repetition. Using 'space syntax' techniques, she studies configurational attributes of buildings including the relational patterns of individual spaces, sightlines, and visual fields. Put simply, space syntax techniques decompose a building layout into a set of rigorously defined discrete spatial units and use graph-theoretic measures to describe the relational patterns of these units. This process of decomposition of a building layout often depends on the purpose of a study. For example, a building layout can be decomposed into a set of convex spaces, where every point can be seen by every other point within each space. The literature on space syntax shows that the relational patterns of the convex units in building layouts are relevant to studies concerning how buildings, through spatialization of functions and social categories, embody and reproduce social knowledge. A building layout can also be decomposed into a set of axial lines needed to cross every convex space and circulation ring in the layout. The relational patterns of the axial lines are relevant to studies concerning how buildings create different conditions for movement, interaction, and co-presence. Additionally, a building layout can also be described as a set of isovists, where every isovist is a 360-degree visual field drawn from each unit of a rigorously defined set of points or spaces in a building layout. The relational patterns of these isovists provide a realistic description of the visual perception of an observer within a building, but they are also relevant to studies concerning spatialization of functions and social categories when used in conjunction with the convex units, and to movement, interaction and copresence when used in conjunction with the axial lines. It is argued in the literature that space syntax techniques work because human behaviors constitute spatial patterns that are generated and sustained by spatial configuration.

In her analysis of building plans, Psarra does not keep the geometric and configurational descriptions of building layouts separate from each other. Rather, she often juxtaposes them with each other. As a result, she is able to identify those instances when these descriptions reinforces one another, when they stand separate from each other, or when they weaken each other in the visual perception of the observer. These instances then provide the basis of her ideas presented in the book.

\section{Basic ideas presented in the book}

Based on her analysis, Psarra makes several observations. First, the geometry and configuration of building impose various degrees of visual restriction on the moving observer. High degrees of visual restriction result in low degrees of perceptual variation, as in Chiswick Villa, or vice versa, as in Soane's Museum. Such perceptual variations, argues Psarra, cause buildings to be understood as different visual and spatial complexes. For example, in Chiswick Villa the visual fields along the main line of movement lack variation and provide comparable information about form and space on either side of the line, thus suggesting a strong sense of symmetry (Figure-1). In contrast, in Soane's museum the visual fields along the main line of movement are considerably different from each other and provide different amounts of information about the form of space as they shift from one side of the line of movement to the other, thus suggesting a strong sense of asymmetry (Figure-2). 
Second, when the geometric order and configurational structure converge to enhance unity in visual experience and to augment the message of the conceptual schemes of displays inside, buildings tend to reduce spatial exploration and observer participation. Conversely, when the geometric order and configurational structure diverge to enhance variations in visual experience and to encourage interpretation of the conceptual schemes of displays inside, buildings tend to stimulate spatial exploration and observer participation. As a result, the first type of building helps conserve meaning, while the second type helps generate meaning.

Third, the relationships between the conceptual and the perceptual in buildings are dynamic, not dichotomous. Sometimes an illusion of dichotomy, often misunderstood as a true dichotomy, may exist between these two realms of buildings. As Psarra puts it: 'The ways in which the two [realms] interact might foreground one realm over the other, creating an illusion of a dichotomy, as in a classical building, where the unchanging views along an axial route highlight the abstract stable order at the expense of a varied visual experience, and in an eighteenth century English garden, where the impression is created of the absence of order' (p. 14).

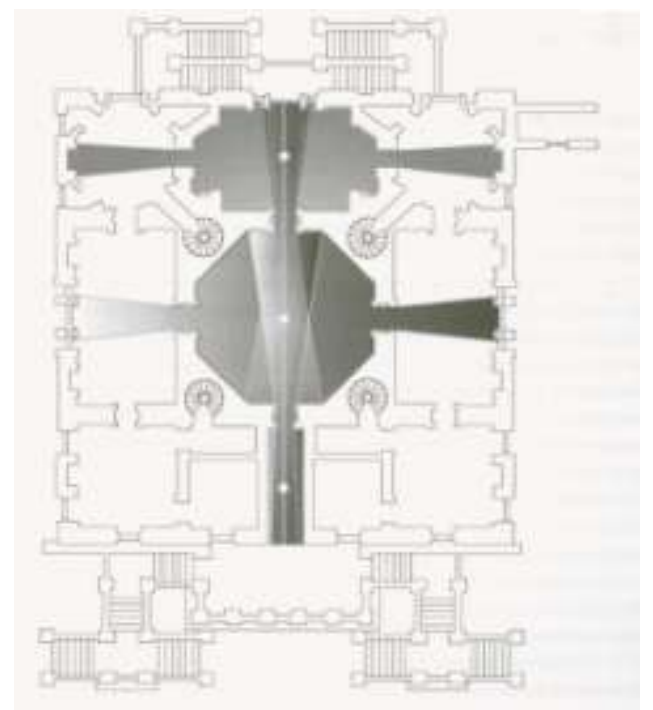

Figure 1(Psarra, 2009, Figure 9.1): Chiswick Villa, London. First floor plan. Isovists from the central axis.

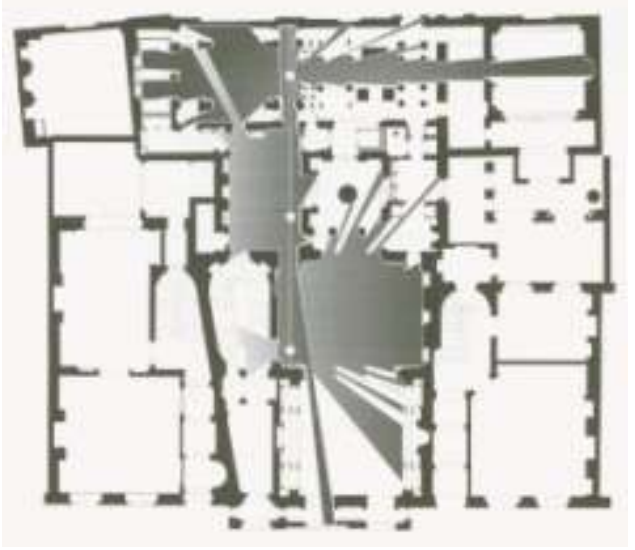

Figure 2 (Psarra, 2009, Figure 9.2): Soane's museum, London. First floor plan. Isovists from Dining Room, Breakfast Room and Dome.

Psarra is remarkably thorough and insightful in her investigation with very few questionable ideas and limitations. Yet her remark that the Parthenon and the Erechtheion 'did not order a set of social relations through their interior spaces' (p. 8) is questionable. It contradicts Hillier's assertion that 'to enclose a space ... creates not only a physical distinction on the surface of the earth, but also a logical, or categoric distinction. ... The logical distinctions made by drawing boundaries are also sociological distinctions, in that the distinction between inside and outside is made by a social being...' It also contradicts Tschumi's assertion that 'there is no space without event, no architecture without a program'.i This is despite the fact that Hillier and Tschumi along with Lefebvre provide the theoretical foundations for Psarra's book. Psarra contradicts them anyway, because she needs to explain why she 
includes the Parthenon, the Erechtheion and the Barcelona Pavilion in her book, even though these buildings do not seem to fit well within her overall intellectual framework.

The uneasy relationship between the intellectual framework and the case studies of the book, however, is pervasive. At times, Psarra's selection of case studies appears arbitrary. For example, despite her attempts to integrate the analysis of Borges' texts within her line of arguments, this segment of the book remains out of place. If the purpose of the book was to study the structure of narratives in different art forms, then it was necessary for her to explain why the study was limited to literature and architecture only. A more appropriate approach would have been to include in her study music, literature, movies, and architecture. Together they would have provided a more comprehensive context for understanding the relationship between the conceptual and the perceptual in narratives.

In this context, Psarra is not careful enough in using her terms. For example, she uses "sensual experience", "visual experience", and "perceptual experience" interchangeably, even though they may mean different things. Most remarkable in this regard, however, is that she also uses "order" and "structure" interchangeably. This is odd, because "order" is distinguished from "structure" in the space syntax literature. Hanson used order for the abstract geometric order and structure for the structure of visual experience ${ }^{\mathrm{iii}}$-a distinction that was further ratified by Hillier. ${ }^{\text {iv }}$ This is an indelible distinction for many students of space syntax. Interestingly enough, Psarra never mentions this distinction suggested by Hanson, even though it seems quite relevant to the subject matter of her book.

Psarra correctly mentions that her book is about architecture, spatial cognition, and meaning (p. 1). One may also suggest that her book is about architecture, visual perception, and meaning. Yet, Psarra never situates her contribution in the literature related to spatial cognition and/or visual perception. Instead, the theoretical synthesis segment of the book includes a lengthy discussion on innovation in architecture focusing primarily on Hillier's ideas. ${ }^{v}$ It is possible that Psarra is a little more precise on the subject of innovation in architecture than Hillier was in his discussion, but this is not where she puts her efforts in this book. Thus, her contributions to spatial cognition and visual perception remain unrecorded in her own book.

To say the least, Psarra's book raises several interesting questions concerning spatial cognition and visual perception in architecture that demand further empirical study. For example, to what extent are visual restrictions imposed by the geometry and configuration of a building able to predict perceptual variations inside the building; to what extent are perceptual variations inside a building related to the understanding of its meaning; to what extent is visual perception associated with exploration of and participation with displays inside a building; to what extent is the observer inside a building able to separate the conceptual from the perceptual; or to what extent do individual, social, and cultural factors modify all or any one of the above relationships? It is not known if enough is already available in the cognitive science and perceptual psychology literature to answer these questions. Given the controlled nature of experimental studies, it is unlikely that studies in these fields would sufficiently inform spatial cognition and visual perception in architecture. For example, in architecture a generation or two back we gave a great importance to the findings of the 2-dimensional studies of Gestalt psychology. Now, we 
know that most of the findings of those studies probably are not relevant to the 3-dimensional or the 4dimensional world (i.e., if time is considered as an aspect of space) of architecture.

The fact of the matter is if the designer is to control how clearly and rapidly the meaning or aesthetic meaning that is embodied in some design is grasped and set on its path to engage the observer, the designer should know if there are rules that govern the perception of meaning, and what they are if they do exist. To the cognitive scientist or the perceptual psychologist the question of perceived meaning in architecture is potentially interesting, but they probably do not have any internal reason to do the kind of systematic research that could be useful to the designer. If an understanding of the relevant aspects of the perception of meaning is to be developed, the designer will have to raise the appropriate questions before the cognitive scientist or the perceptual psychologist can reasonably be expected to attempt an answer. This is exactly what Psarra has done in her book Architecture and Narrative.

Some observations are also in order concerning the research techniques used in Architecture and Narrative. Throughout the book, Psarra insists that there is no dichotomy between the conceptual and the perceptual in architecture. Every building makes investments in both these realms, sometimes foregrounding one over the other. Therefore, the conceptual and the perceptual are dynamically related to one another. What one takes from this is that architecture, as defined by these two realms, can be characterized on a continuum ranging between something that foregrounds the conceptual over the perceptual and something that foregrounds the perceptual over the conceptual. Regarding research techniques, it is clear that if the conceptual and the perceptual are described using two set of unrelated techniques-one set describing geometric properties and the other set describing configurational properties - then the dynamic relationship Psarra wishes to describe cannot be described using these techniques. The dynamic relationships between the geometry and configuration of architecture calls for a set of techniques that would help resolve their distinctions. In the absence of these techniques, the synthesis of the conceptual and the perceptual in architecture can happen only in the mind of the author, as is the case in Architecture and Narrative. For many, this arbitrariness in interpretation may become a source of distraction despite Psarra's laudable efforts toward achieving objectivity.

This methodological limitation is certainly not unique to Psarra. Traditionally, architectural description was focused on the shape (i.e., the physical form) of architecture. The traditional architect used the same geometric tools, such as axiality, centrality, symmetry, rhythm, congruence and repetition, which Psarra uses in her book. There were even a few more tools and techniques in the repertoire of the traditional architect, such as the systems of geometric transformations and proportions, which Psarra does not use. In contrast, space syntax theories and techniques describe spatial form or configuration based on topology that the traditional geometric tools could not describe. Therefore, Psarra uses both because she is interested in the relationship between the physical form and the spatial configuration of architecture. However, no theoretical integration between the traditional geometric techniques and the more recent space syntax techniques - of the kind attempted by Peponis and his colleagues ${ }^{\mathrm{vi}}-$ is provided by Psarra. It is possible that a more objective discussion of the relationship between the conceptual and the perceptual, or the visible and the invisible, or the physical and spatial form of architecture would come from a set of theories and techniques that show how to integrate the 
geometry of the shape with the topology of space. There is still a lot more than what Peponis and his colleagues had already proposed that needs to be done in this regard. vii

Despite its limitations, this book is a significant addition to the space syntax literature. It is among the very few books written using space syntax theories and techniques, and probably the third book of its kind that focuses primarily on buildings. It is certainly a unique book on the study of museums. The book makes architectural description richer by constantly referring back and forth between the conceptual and the perceptual, and between the geometry and the configuration of architecture. Written in the tradition of Colin Rowe and Robin Evans, this book is a step forward for its insistence on representing ideas in diagrams. The reader is encouraged to compare Evans' 'Mies van der Rohe's paradoxical symmetries'viii with Psarra's 'Invisible surface' (ch. 2)-both written on the Barcelona Pavilion. While much is hidden in the rhetoric of Evans' text, Psarra exposes almost everything in her diagrams. Her analytic diagrams in Architecture and Narrative are superb. The book is worth having simply for these, which surely would have their own impact on the reader over and above the impact this book is likely to have for its insights on architecture, visual perception, and meaning.

Architecture and Narrative is a complex book. If the reader wants to understand the arguments presented in the book, she should read the introduction first and then the chapter "Comparative Discussion" in the theoretical synthesis segment of the book before she reads the other chapters. However, the reader may also read any one of the chapters independently. These chapters would make good sense on their own, because the arguments presented there are almost self-contained.

Mahbub Rashid

University of Kansas

USA

'Bill Hiller, Space is the Machine, Cambridge: Cambridge University Press, 1996, pp. 15-16.

ii Bernard Tschumi, Architecture and Disjunction, Cambridge, MA: MIT Press, 1999, pp. 141. Quoted in Psarra, p. 234.

iii J. Hanson, 'Order and structure in urban design', Ekistics, 334-335 (1989): pp. 22-42.

iv Bill Hiller, 'Time as an aspect of space', Space is the Machine, Cambridge: Cambridge University Press, 1996, Chap. 6, pp. 171-189.

'Bill Hiller, 'What architecture adds to building', Space is the Machine, Cambridge: Cambridge University Press, 1996, Chap. 1, pp. 10-38.

vi John Peponis, Jean Wineman, Mahbub Rashid, Sonit Bafna, Sung-Hong Kim, 'On the description of shape and spatial configuration inside buildings: convex partitions and their local properties', Environment and Planning B: Planning and Design, 24 (1997): pp. 761-781.

vii Mahbub Rashid, On the configurational studies of building plans from the viewpoint of a situated observer, PhD dissertation, Georgia Institute of Technology, Atlanta, 1998.

viii Robin Evans, 'Mies van der Rohe's paradoxical symmetries', AA Files, 19 (1990): pp. 56-68. 